\title{
The Counterphobic Defense in Children
}

\author{
Elva Poznanski, M.D., Children's Psychiatric Hospital, Ann Arbor, Michigan
}

Bettie Arthur, Ph.D., University of Michigan Medical Center, Ann Arbor, Michigan

\begin{abstract}
The clinical data for this study were derived from the case histories of five children who consistently used the counterphobic defense either alone or in combination with phobic attitudes. The children's manifestations of this defense appeared in both verbal and nonverbal behavioral patterns. The choice of defensive style was found related to at least three factors: an early history of trauma, especially separation, parental encouragement of "toughness," and essentially a counterphobic family style.
\end{abstract}

During the course of development, most children experience and express transient fears. In a few children, acute fears become chronic and exaggerated to the degree that they constitute a major portion of the child's psychopathology. Although the ways in which the children respond to their own fears are diversified, it is only the occasional child who reacts both by vehemently denying his fears and by reinforcing this denial with a counterphobic defense.

The origins of the counterphobic defense in children are likely related to the child's frequent use of play to master anxiety. In play, situations simulating a wide variety of life experiences are reenacted. The child adopts various roles (e.g., Indian, soldier, teacher, mother) each of which affords a means of alleviating the anxiety attendant on the expression of the impulses around the simulated life situations. In a sense, then, play activities can be considered a form of embryonic experimentation with the counterphobic stance. Normally the child does not so accentuate the use of this device that his entire personality becomes organized around this defensive maneuver. It is only when the child's fears are reinforced to an unusual degree as a consequence of his personal life experiences, as well as by contributions from his own innate temperament, that the need to counteract overwhelming anxiety is achieved in this way. Counterphobic attitudes promote the proliferation of defensive denial accompanied by the nonverbal acting out of the conflict. The presence of the counterphobic defenses in children does not achieve the virtually complete 
diminution of anxiety seen in adults, as the transformation of anxiety via libidinization of the counterphobic acts is never complete.

There are only a few papers in the literature that deal directly with the counterphobic defense $(1,2,3,4)$. All of these deal with adult case material. At Children's Psychiatric Hospital, Ann Arbor, Michigan, we have encountered 5 children, all boys, who have manifested this defensive stance either alone or in combination with phobic attitudes. The 5 cases were culled from records of 867 children seen for evaluation over a two-year period. The incidence of counterphobic conditions in childhood is quite rare (well under 1 percent) even though phobias are relatively common (about 5 percent). The case histories of these 5 patients will be briefly presented to provide background information for a discussion of ego development, with reference to the structure of the counterphobic defense in children.

\section{Case Histories}

\section{Case 1}

Eleven-year-old Bert was referred for psychiatric evaluation by the Urology Department because of enuresis. Three months prior to evaluation, Bert had undergone a second operation for undescended testicles, the first stage having been completed six months prior to that.

Bert was a red-haired, freckle-faced, amiable youngster who was eager, friendly, and bubbling with self-confidence. He had a cast on his right hand, applied in the emergency room the night before the psychiatric interview, for a fracture of the fourth and fifth metacarpal bones. Bert talked easily but displayed impulsivity in his lack of reflection about his answers. Even as he responded to questions, his body was in continual motion. Bert immediately denied having any problems and directly stated that he considered the psychiatric referral unnecessary. When the discussion centered on his bed wetting, he talked at length about his surgery and the extensive testing done during his hospitalization. At this point, Bert denied being frightened or apprehensive at any time, saying he was "scared of nothing" and that he had never been scared because he was strong. He talked proudly about having to go to the hospital almost every month for sutures in his knees, elbow, forehead, and so on. When asked for his earliest memory, he related the scene of his first accident. He remembered he was very small, that his right hand was covered by a bandage, and that it hurt. When asked, he quickly denied that he had been frightened. Nevertheless, on further probing he did admit that he was a "little 
frightened" by the episode. He denied dreaming but made a slip of the tongue, saying that he just had nightmares, not dreams. Further material about his nightmares could not be elicited.

In school, Bert was about 1 year retarded academically. Defiant toward authority, he generally got along well with his classmates, winning their respect through his athletic ability. Exceptions to this adjustment arose from his "throwing a punch" here and there and having occasional temper outbursts. Intellectual functioning on psychological testing done at school gave him a WISC full-scale IQ of 113 (verbal IQ was 109 and performance IQ 115). The range of abilities extended from an $8 \frac{1}{2}-$ year age equivalent in arithmetic to a 16 -year age equivalent on tasks depending on visual alertness and immediate auditory recall.

Bert's parents clearly demonstrated their resistance to psychiatric evaluation. They came very late to the interview, then verbally echoed their son's feeling that psychiatric treatment was not needed, and finally gave as their reason for coming that Bert's urologist had requested it.

Bert's development was described as normal in the early months, with such accomplishments as walking and the speaking of single words occurring before one year. At 14 months, Bert cut one of his fingers so severely that suturing and immobilization were required. His mother recalled that he was so frightened by this experience that he stopped talking until he was three years old. Since the time of that accident Bert had become accident prone and had made innumerable visits to the emergency room.

The mother talked about Bert's enuresis and said that they had tried various devices and treatments without success. They had not tried the alarm belt because "it might shake him up." (Incidentally, the parents later tried the alarm belt against medical advice.) Regarding other unusual behavior on Bert's part, the only incident that the mother could recall occurred when Bert was four years old. She said that Bert used to have nightmares and one night woke up screaming that there were frogs in his bed. He did not calm down, despite his mother's efforts. His terror was relieved only when his father came into the room and pretended he was killing all the frogs and throwing them out of the bed.

The mother described Bert as having been an extremely hyperactive, accident-prone child all his life. He was extremely aggressive with his peers at school, "always fighting." He definitely did not like to be kissed or to be considered weak or a sissy. The mother felt that his attitude was linked to the father's insistence that Bert not express any fear or weakness because he wanted him to be "a man." The mother expressed some concern over the fact that her husband was extremely controlling and punitive with Bert. The father always wanted to know where Bert was going, the length of time he would be at any one place, and rigidly demanded that Bert not move from the place he said he was going under any circumstances. 
Bert's father was a tall, blond, worrisome-looking man who wanted to give an impression of strength, but his insecurity in this regard was quite apparent. $\mathrm{He}$ felt that Bert's enuresis was a personal embarrassment and preferred to think of this enuresis as being on an organic basis. Later in the interview, when the psychiatrist commented that Bert's early injury and hospitalization had so frightened him that he still had difficulty talking about it, the father's attitude toward this was summed up in his response of "Oh, golly! and I thought I had a real masculine boy." Initially, the parents reluctantly agreed to try psychotherapy. Imipramine was prescribed for the enuresis but later was stopped by the parents. The parents rather quickly eased themselves out of therapy by giving numerous excuses for not coming to appointments, hiding behind Bert's statement of not liking to come, and refusing to examine their own behavior as having any relationship to Bert's response.

\section{Case 2}

The referral of nine-year-old Don listed the following causes for concern: $(a)$ lack of respect for school authorities; (b) hyperactivity in school and at home; $(c)$ overly aggressive with other children and frequently starting fights; and (d) exaggeration and lying.

Like Bert, Don had had a series of early hospitalizations and surgical procedures that caused separations from the family combined with potentially fearful situations. At $1 \frac{1}{2}$ months he was hospitalized for five days with diarrhea and vomiting; at 3 to 4 months he was hospitalized for one week with pneumonia. Both times his mother stayed with him. At 16 months he had a herniorrhaphy which was performed in the outpatient department. A T\&A was done at five years, for which he was hospitalized for two to three days. During this hospitalization the mother did not stay with him. While none of these hospitalizations were medically serious, the total number was somewhat unusual for age five.

The family moved to the United States from Germany when Don was 2 years old. Don had been bladder trained prior to the move, but after the move he became persistently enuretic. Don was described as "dawdling over food" and as having been an extreme feeding problem until age $2 \frac{1}{2}$, when his difficulties eased somewhat, although he continued to be a "slow eater."

Don was a handsome boy, neatly dressed, who initiated the interview by saying, "I'm bad, but I still pass in school. I act up. I try to get along, but end up in trouble every day unless I'm at someone else's house. That's when I'm good because they get along with me and like me. They don't know how I am-bad, that is. My brother and dog don't like me because I always fight with them." $\mathrm{He}$ 
then asked if people were allowed to stay at Children's Psychiatric Hospital. When told they were allowed sometimes, he said, "I'd like to stay here a couple of days and see what it's like. I want someone to help me so I won't get into so much trouble. They tried everything, and it doesn't work. When I do something, I don't want to do it, but something in here [pointing to his head] will tell me to, and I can't help doing it." He related that his father was too strict with him and always told him no. Don said, "He doesn't trust me because I do stuff that I'm not supposed to do. I remember once he threw me against a wall because I had four shiny rocks in the house and he didn't like it." When asked if it was not pretty frightening to have his father throw him against a wall, he said with much bravado, "I'm not frightened of anything. I stand up and fight. I learned this from watching TV. People who get scared are weaklings and don't know how to fight. When I grow up, I'm going to be a fighting man. Babe Ruth was a fighting man. It's important to fight because everybody says 'Hooray' for you." On leaving the interview, he said that his parents had tried everything but "putting me in a place like this. I'd do any thing to help."

Psychological testing done at the local school because of the school's concern that his behavior might have an organic basis did not show any organicity. On these tests his intelligence was rated in the normal range; yet he had repeated the third grade and was currently performing very erratically academically with his grades varying from " $F$ " to " $B$ " on the final report.

The mother, a German war bride, married the father after Don's conception. She denied that it was a shotgun wedding. She expressed concern over the father's rigid punishment but felt that she herself was "too lenient" with Don. All other evidence is suggestive of a rather distant relationship between mother and son and his behavior "perplexing her."

Don's father was rigid, perfectionistic, and lacking in warmth. He had chosen a career in the air force. Previously, although one of the amphetamines prescribed by a local physician had helped Don's hyperactivity considerably, his father had stopped the medication because "he can't take pills all his life." The father's disciplinary techniques with Don included physical punishment, isolation, and verbal reprimand, all without much success. Prior to being punished Don appeared indifferent; afterward he was remorseful.

Following the psychiatric evaluation, the parents complained that the psychiatric interviews had not been helpful and refused to become involved in therapy despite strong recommendations that this was indicated.

\section{Case 3}

Adam was an eight-year-old Negro boy, referred by the school social worker following his suspension from school for hyperactive and aggressive behavior. 
Adam's twin brother manifested similar behavior problems. However, only Adam's case is presented because the counterphobic elements are more clearly evident.

Adam came from a multiproblem family, which had functioned in a chaotic and unorganized fashion since his earliest years. The facts about Adam's early life were meager because of the mother's limited ability to act as a historian. Nevertheless, traumatic events were prominent and again produced painful separations. When Adam was two years old he witnessed the "crib death" of a baby sister. At three he witnessed a particularly brutal episode in which his stepfather beat his mother unmercifully. Amidst much screaming, the stepfather grabbed a pistol and shot at Adam's mother several times. He missed killing her but then ended up by whipping her with the pistol. The commotion was great enough to disturb the neighbors who called the police. When the police arrived, the mother was in shock and taken to a hospital. At the time of the evaluation the stepfather had disappeared from the home, as had Adam's natural father. These separations were recorded; however, additional unrecorded separations could easily have occurred in so chaotic a family setting.

Even at the time of Adam's evaluation the mother appeared depressed, anxious, physically ill, and accepting of, and perhaps eager for, placement of the boy.

Adam himself was aggressive and negative during the psychiatric interview. He immediately let the psychiatrist know that he did not want to come to this interview. His matter-of-fact attitude about his past experiences seemed overdone. Adam was always physically active. He played constantly with the ashtray, stabbing at the butts, mashing the ashes with a pencil. He refused to play with any of the toys in the office. His attention was visibly distracted by the phone, the lights, and the fan. Some of Adam's activity appeared to be a way of warding off disturbing ideas.

In school, Adam's teacher reported a decrease in his hyperactive behavior whenever a neighbor, rather than his mother, cared for the family. His intelligence was within the average range as measured by the WISC. Adam was placed at grade level but was underachieving. The teacher thought he understood concepts but was unable to apply them.

Adam manifested both phobic and counterphobic elements in his adjustment pattern. He feared bugs and other animals in a concrete yet unconsciously symbolic manner. When confronted with a frightening reality, however, he would almost immediately resort to defensive denial of its aggressive connotation. His avoidance of frightening thoughts was illustrated when he was asked to make up a story about a little dog being spanked. Adam's response was that it was the little dog's birthday and his mother was giving him a brithday spanking.

Since the school social worker handled the disposition of the case, the final outcome is not known. 


\section{Case 4}

Peter was only four years old when his parents brought him for psychiatric evaluation because of their concern about his intellectual potential, his fears, and fighting with his younger brother Mike.

As early as 18 months, the mother had complained to his pediatrician about Peter's tantrums, crying spells, and resistance to discipline. When Peter began to speak he immediately displayed his fears and demonstrated an active imagination. At 2 years, when a younger sibling was born, Peter was in a near panic when his mother had to go to the hospital. Since this reaction is unusually intense even for a 2-year-old, it suggests that earlier experiences had "conditioned" Peter to react to separation with intense anxiety. When Peter was $2 \frac{1}{2}$ years old, the mother had to take him to a child guidance clinic for help in managing his tantrums and aggressiveness toward his baby brother. When Peter was 3 years old, a third child was born. At this time Peter, who had been bladder trained for 6 months, became enuretic and was still so when seen at Children's Psychiatric Hospital.

The father appeared as a quiet, reserved young man, who conveyed the impression of needing help and support. At the time of the evaluation he was a graduate student and had received psychiatric help himself from the Student Mental Health Center. Long-term therapy had been advised for the father, but he had decided against it, feeling that he would "grow out of it." The mother appeared young, anxious, and naïve. She attempted to give "educated answers" but denied any feelings of her own. In their marriage, both parents used a great deal of denial, including denial of the fact that conception of Peter had, in fact, precipitated the marriage. Their denial of their feelings extended to many other areas, including their relationship with their in-laws, future plans, and aspirations for themselves.

Peter demonstrated both the direct expression of fears and the denial of fears during the same interview. When the psychiatrist asked Peter to point to his nose, he replied, "See, there's no blood on it." Peter's numerous fears were evident from his expressed concern about dragons and crocodiles during play sessions. While listening to a "Peter and the Wolf" record, he identified with "poor little Peter" who had to go out unprotected into the forest without a gun. In the story "Jack and the Beanstalk," Peter's concern was about the giant who "eats little boys on toast." During these times, Peter's anxiety about oral-aggressive themes was manifested by his suddenly needing to go to the bathroom. At one time Peter became so overpowered by his fantasy material that he would unexpectedly demand absolute control over what he did and did not play during the interview. When these demands were not agreed to, his counterphobic stance failed, and disruptive anxiety appeared. Peter then expressed feelings of helplessness and of being hurt by the physician. 
After the diagnostic evaluation, the recommended therapy could not be initiated because the parents decided to move to another area where, incidentally, psychiatric treatment would not be available.

\section{Case 5}

Andy was a 12-year-old boy referred by the school with parental concurrence for poor academic achievement, temper tantrums, and the use of obscene language.

During the psychiatric interview, Andy presented himself as a timid, sensitive youngster, somewhat small for his age, who was quite afraid of his father. He spoke openly about his fears of getting hurt and how he avoided sports, climbing trees, and other activities that he felt might be dangerous. Indeed, he would often talk another child into doing something first in order to test out its safety.

Andy's employment of a counterphobic defense was limited to reading and fantasy. Here he showed a tremendous interest in mystery stories in which people hovered on the brink of losing loved ones or their own lives through "accidental" events. Andy was fascinated with hunting and war stories, to a degree that had interfered with his ability to concentrate.

Andy came from a middle-class family that was striving for a high standard of living and concentrated their hopes and ambitions on Andy, their firstborn. The mother expressed her concern that they had been too strict with him, commenting that they had "eased off" with the younger children. The father had recently suffered a demotion at work, which caused further deterioration in an already poor relationship with his son because of the father's own frustration with himself. Andy's parents initially accepted the offer of outpatient therapy, but their commitment lasted only two to three months. The therapy was discontinued partially because of the strong desires of the parents to "go it alone" and partially because the boy was showing some improvement at that time.

\section{Discussion}

Because of the small sample available, the fact that all five of the above cases were boys cannot in itself assume significance. However, Weissman (4: p. 490) in writing about the counterphobic defenses comments: "I have not seen a true counterphobic in a female patient." Since his experience and that of the authors tally, it may be that cultural factors relating to attitudes about handling aggression and dependency might play a determining role in the choice of the counterphobic defense. 
The first three cases showed a fairly consistent use of the counterphobic defense, with little open expression of fear. The last two cases were children with mixed phobic and counterphobic attitudes. To some extent the first three cases resemble each other, as do the last two cases. The first three boys were hyperactive and aggressive children with obvious deficiencies (i.e., they had learning disturbances, difficulty in relating to adults, massive use of denial, poor impulse control, and the like) whose parents could not admit there were serious problems. In the last two cases, the children were more verbal, used a wider variety of defenses, and the parents were more concerned about them.

\section{Significant Factors in the Choice of Defense}

Outstanding in the early development of these counterphobic children is a history of early separation from the parents. Particularly in the first three cases, the separations were repeated and were associated with some sort of traumatic event. Case 1 injured his hand at 14 months, an event frightening enough to have stopped further speech development until 3 years of age. The fact that the anxiety around the accident was still manifest 10 years later, during the psychiatric interview, in the production of the memory accompanied by counterphobic attitudes vividly states the psychic impact. The mother's comment that after this accident the child became "accident prone" suggests a counterphobic mechanism for this child's accident proneness. The later hospitalizations seem to augment the early unsolved fears of injury. In this case in particular, it would appear that the child had a strong need to master the anxiety associated with injury. The later traumas compounded the feelings about the original one, perpetuating the anxiety on so high a level that a constant counterphobic stance was consolidated. Case 2 had several hospitalizations before the age of 5 . Case 3 had witnessed the crib death of a sibling and many violent scenes, including one where the mother was brutally beaten, all before he was 4 years of age. These facts strongly suggest that early traumatic events set the stage for a child to adopt a counterphobic defense. The intensity and frequency of the traumatization produce a cumulative effect with little opportunity for the child to master the anxiety between the events. Abetting the child's inability to cope with the anxiety is the family's failure to use verbal techniques for dealing with critical events. They tend, instead, to rely on action rather than thought. The child adopts this model, and hence, the relief of anxiety becomes unavailable except at a body language level. Further development of this response is likely reinforced by the parents' use of denial, including the denial of the fear-producing nature of the experiences the child has had. 
The quality of the relationships between the child and his parents can influence the child's behavior. Overall, the mothers seemed relatively unconcerned and uninvolved considering the severity of the child's problem. This not only tends to make the child more vulnerable to trauma, since the mother is not providing as much protection from traumatic incidents as she should, but also forces the child to be more self-reliant in managing crises. He must handle them himself, since there is no one to help him with them. He then models his management techniques after those he observes in his parents-techniques that deny anxiety.

The fathers, or father substitutes, encourage "toughness" and denial of fear in their offspring. Bert's father responded to the admission of fear by his son with, "I thought I had a real masculine boy." This type of response is typical of the entire group. Two of the fathers stopped their sons from taking medication because such behavior represented "weakness" to them. All of the fathers were described as cold, tough, reserved characters, capable at times of violent interaction with the environment. The boys, by taking a counterphobic stance, were able to fall into the familiar "identification with the aggressor" type of relationship with their fathers.

One cannot help but be impressed that these children did have ego strengths as well as deficits. Generally, they were able to form friendships with peers, function intellectually, al though not up to full capacity, and in some instances demonstrated mastery of special skills. They did show neurotic and characterological symptomatology, but none were borderline or psychotic. It is well known that autistic and schizophrenic children show intense fears but are unable to cope with or defend against them. The employment of the counterphobic defense appears to be a sign of ego strength; while the fears of our young patients were strong, they did not completely overwhelm them.

The attitudes of the parents were particularly striking in that, like their offspring, they were essentially counterphobic. The father in case 1, who stopped his son from having nightmares by pretending to kill the frightening but imaginary frogs the son was screaming about in the middle of the night, certainly provided a vivid model for the adoption of the counterphobic defense. By his actions, he demonstrated agreement with his son's fears and proceeded to physically demonstrate the necessity of action.

The parents' feelings about their children taking medication, as shown in cases 1 and 2, seem also to stem from counterphobic attitudes. Their fear of addiction shown by the statement "He can't take pills all his life," and the subsequent rejection of medication even when it was helpful, reflects the strength of the underlying need to avoid dependency. The relationship between addiction and the counterphobic mechanism in adults has been described in great detail in a paper by Szasz (2). The parents' reluctance to use medication 
reflects an underlying fear that addiction, which is equated with dependency on something outside of the self, will prove weakness. A strong need to demonstrate adequacy is, in this way, related to the counterdependent mode, a context in which the counterphobic stance is tenable.

Counterphobic behavior was also seen in the parents, relative to seeking psychiatric help. Schools and physicians, in managing to have the children evaluated, had to overcome great parental resistance. Only in the last two cases, where mixed phobic and counterphobic behavior was seen in the children, were the parents at all even ambivalently interested in seeking out psychiatric referral. At the time of disposition, the reluctance of nearly all the parents to become involved in treatment was striking. It appears that the parents of the first three cases were denying the reality of their children's problems, while the parents of the last two cases were phobically avoiding treatment.

Certainly the parents' use of counterphobic attitudes both in their own lives and in their relationships to their children facilitated the adoption of the counterphobic stance in the child.

\section{Nonverbal Counterphobic Attitudes}

While verbalization of the defense and discussion of the underlying content weaken the defense, in daily life these children do not regularly employ verbal techniques for dealing with anxiety. Kahn (3) has commented on the manner in which the counterphobic defense is linked to the impulsive acting out of anxiety. In these children, nonverbal behavior often serves as the main vehicle for the expression of the counterphobic defense. There is a reciprocal relationship between the expression of anxiety through motoric channels and the adoption of the counterphobic defense.

An attitude of defiance toward adults by these children was common. Defiance generally connotates swaggering confidence; yet in the case histories there was evidence of adults behaving in an anxiety-producing manner (e.g., Don's father, who threw him against a wall in a rage). The mother's report of the fear of the father was an accurate perception on her part. The defiance, then, represents an overcompensation for underlying fear-a means of denying weakness, vulnerability, and the attendant anxiety. In addition, adoption of the defiant stance kept alive the hope that acceptance, which was conditional on toughness, could be achieved and thereby afford relief of victimization and the anxiety aroused by anticipation of further injury.

In these children, fighting also served as nonverbal counterphobic behavior. Bert and Don felt that not to fight was "sissy." The defensive nature of this attitude is apparent from the fact that it was fighting itself that was valued, not 
fighting as an instrumental act to achieve a limited objective. Constant fighting proved their "toughness" to themselves. The underlying fear of injury was denied as the fears in connection with early traumas were denied. Allied to this, the hyperactivity with its aggressive components also played a role in the counterphobic stance. In Adam's case, the hyperactivity was quite directly related to the chaotic, violent, and frightening home situation. It decreased significantly when he was cared for by a mother substitute, thereby demonstrating that it was unnecessary when the environment was nonthreatening. The first three boys were all hyperactive and aggressive. There was a continuous discharge of aggression through bodily activity. They expressed in this way the anxiety based on hostility toward adults perceived as threatening. These children clearly were committed to physical mastery as manifested in the degree and intensity of their activity. By projecting their own aggression and then assuming the counterphobic stance, they were then able to externalize their problem. Reexperiencing the traumatic events that were previously passively endured gave a sense of mastery. The two boys who had the mixed phobic and counterphobic picture could use other defensive mechanisms in addition to projection and denial. Part of their struggle was carried on intrapsychically, and consequently there was less overt aggressive behavior noted.

\section{Theoretical Considerations}

Whenever the counterphobic attitude is examined in detail, primary anxiety is observed in some form. Fenichel (l) stated that within the counterphobic attitude there were "leakages" of anxiety. The histories of these children reveal anxiety breaking through in a number of different ways: nightmares, hyperactivity, and overt anxiety during the interviews. The presence of the tremendous anxiety held in check by this defense was best illustrated in case 4 . where initially during the interview the child showed strong counterphobic attitudes. Later, when presented with story material that provided a safe vehicle for the expression of anxieties about potential destruction, these defenses crumbled, and Peter identified with the victim instead of the aggressor. This shift in identification was accompanied by an attitudinal change from a state of confidence to near panic.

The close relationship between the defense mechanism of denial and the counterphobic defense is perhaps illustrated best in case 3 . Although this child used both defenses, the existence of the counterphobic attitude was actually brought out best in psychological testing where on the projective tests he used the noun "bugs" to represent the concrete object and in an unconsciously symbolic manner to stand for dislikes and fears. During the psychiatric 
interview, denial overshadowed the counterphobic defense. The type of denial used by these children is related to "denial in the service of the need to survive" (5: pp. 118-27). This form of denial is universal and is shown most dramatically and in its healthiest form in individuals denying severe illness or undertaking courageous feats on the battlefield. This particular use of denial, in order to exist in one's everyday life, is differentiated from neurotic denial which has its roots in unconscious conflicts. A continuum does exist between the two types of denial, however. Geleerd (5: pp. 118-27) commented that the blending of the two types of denial can be very subtle and the ability to keep some separation is dependent on good object relationships. To some extent it appears that the counterphobic defense employs both types of denial. Realistically, these children need some sort of denial to endure their environment. For them, some "denial in the need to survive" is healthy.

Fenichel (1: p. 266) described the pleasurable element in the counterphobic defense stating, "Pleasure is the basic component of the counterphobic attitude." He described the "libidinization of fear" as occurring both as primarily, that is, as a result of the early fear experience itself, or as secondarily from other outside, nonfearful experiences that were in themselves not related to the development of the counterphobic defense. Bert's pride in his numerous trips to the emergency room and Andy's fascination with mystery stories indicate that their fears had become libidinized. It should be noted that Bert and Andy were the two oldest boys in the group, being 11 and 12 respectively. The other three boys did not reveal the same degree of libidinization of fear. While evidence on the age at which libidinization was first noted is lacking, its clear existence in only the two older boys with relatively mature ego structures raises the issue of whether secondary libidinization can only occur in children when more complex structuring and organization of the ego develop.

The counterphobic defense maintains its existence through bypassing the reality testing of cognitive activity function. Counterphobic acts are neither logical nor in accordance with reality. They are rooted in primary process functioning and in pregenital fixations which permit a state of omnipotence to prevail together with denial of reality and a belief in the magic of the act. Often they are expressed in nonverbal behavioral equivalents. At the ego level, the skills needed to adapt to and/or cope with reality are impoverished: (a) reality testing is defective; $(b)$ drives are still acted out, not channeled into more appropriate avenues of expression; (c) thought processes seem impoverished to some extent, and thinking is little used as trial action; $(d)$ defensive functioning is stereotyped and defenses primitive; and $(e)$ object relationships are arrested at a level that reflects the failure of integration of a realistic self-representation (i.e., there is a fantasy-dominated self-image as omnipotent, as evidenced by the view that objects are either totally powerful or are not powerful). The major 
barrier to the resolution of the child's problem lies in the resistance of the parents to abandon their defensive attitude toward admitting a problem exists and to accept the need for treatment.

Dr. Pozanski is Assistant Professor in Psychiatry, University of Michigan Medical School, and Staff Psychiatrist, Children's Psychiatric Hospital, Ann Arbor, Michigan 48104.

Dr. Arthur is Associate Professor, Departments of Psychology and Psychiatry, University of Michigan Medical Center, and Assistant Chief Psychologist, Children's Psychiatric Hospital, Ann Arbor, Michigan 48104.

\section{References}

1. Fenichel 0: The counterphobic attitude. Int J Psychoanal 20:263-74, 1939.

2. Szasz TS: The role of the counterphobic mechanism in addiction. J Amer Psychoanal Assoc 6:309-25, 1958.

3. Kahn MM: Role of Phobic and counterphobic mechanisms and separation anxiety in schizoid character formation. Int J Psychoanal 47:306-18, 1966.

4. Weissman P: The counterphobic state and its objects. Int $J$ Psychoanal 47:486-90, 1966.

5. Geleerd E: Two kinds of denial. In M Schur (Ed), Drives, Affects, Behavior, vol 2. New York, International Universities Press, 1965. 